\title{
As TIC como vetores para a democracia e empoderamento em processos de informação, comunicação e conhecimento
}

\section{ICT as a vector for democracy and autonomy in the processes of information, communication and knowledge}

\author{
Patricia Zeni Marchiori ${ }^{1}$, Andre Luiz Appel ${ }^{2}$, Eduardo Michelotti Bettoni ${ }^{2}$ \\ ${ }^{1}$ Universidade Federal do Paraná - UFPR, Brasil \\ ${ }^{2}$ Grupo de Pesquisa UFPR/CNPq - Metodologias para Gestão da Informação, Brasil
}

Autor para correspondência/Mail to: Patricia Zeni Marchiori editoratoz@gmail.com

Copyright (c) 2016 Marchiori, Appel \& Bettoni. Todo o conteúdo da Revista (incluindo-se instruções, política editorial e modelos) está sob uma licença Creative Commons Atribuição-NãoComercial-Compartilhalgual 3.0 Não Adaptada. Ao serem publicados por esta Revista, os artigos são de livre uso em ambientes educacionais, de pesquisa e não comerciais, com atribuição de autoria obrigatória. Mais informações em http://ojs.c3sl.ufpr.br/ojs2/index.php/atoz/about/submissions\#copyrightNotice.

Diferentes ciclos de TIC trouxeram em seu bojo a promessa da democratização dos processos de criação e acesso à informação para os cidadãos em geral, potencialmente empoderando suas ações via um amplo leque de plataformas, cujas interfaces são desenhadas para o envolvimento contínuo deste indivíduo e seus relacionamentos pessoais e profissionais. Tais condições vem se cumprindo em menor ou maior grau frente a entornos de forte globalização de fluxos comunicativo/informativos e, o que poderia ser considerado uma fragilidade, torna-se um ponto de inflexão crítico nas discussões relativas ao trinômio informação/comunicação/conhecimento. A diluição de fronteiras entre a gestão da informação no mundo do trabalho e a que ocorre na prática da vida privada - facilitada principalmente pelo crescente uso de dispositivos digitais de uso pessoal - intensifica mudanças nos critérios tradicionais de qualidade da informação, as condições de seu armazenamento, na disseminação e discussão "em tempo real"e nas medidas que comprovam sua validade.

São estes alguns dos pontos explorados pelos autores nesta edição da AtoZ. Artigos e short papers apontam na direção da aprendizagem apoiada em recursos da informática, como é o caso do uso do Twitter como apoio para um role play game para o ensino de história latino-americana; a discussão de uma metodologia para a criação de software e sua efetiva aplicação para o desenvolvimento de raciocínio lógico-matemático; a construção de espaços pessoais de aprendizagem (PLE) tanto como estratégia de ensino como recurso para a educação continuada dos discentes; e as condições de envolvimento (e o impactos) de posts no Facebook relativos à atividades pedagógicas em escola de ensino infantil. Outro artigo explora os espaços físicos compartilhados, na modalidade de coworking, os quais estimulam práticas e trocas intensivas de conhecimentos e habilidades dos "conveniados", assim como lançam desafios à gestão coletiva dos recursos humanos, físicos e financeiros. E, mais uma vez, as tecnologias vêm em apoio ao processo de comunicação científica, na proposta e avaliação de um modelo LaTeX para curso de Pós-Graduação, com especial destaque às vantagens de sua utilização. Assim, é oportuna a entrevista com Iara Vidal, que apresenta conceitos, características das "Altmetrics"e seus desafios frente a condições diferenciadas (e cada vez mais amplas) de produção e consumo de informação.

Aproveitamos a oportunidade para destacar as novidades da Revista neste 2o. semestre de 2015:

a) Novos indexadores: Nesse último semestre, a AtoZ passou a contar com o registro em dois novos catálogos de revistas científicas: 1) base Información Bibliotecológica Latinoamericana (INFOBILA), da Universidad Nacional Autónoma de México (UNAM), e; 2) base Red Iberoamericana de Innovación y Conocimiento Científico (REDIB), gerenciada pelo Consejo Superior de Investigaciones Científicas (CSIC) da Espanha. Neste período, a equipe editorial da AtoZ também submeteu proposta de indexação pela base Red de Revistas Científicas de América Latina y el Caribe, España y Portugal Scientific Information System (Redalyc), da Universidad Autónoma del Estado de México (UEAM), que se encontra em fase de avaliação. Tais iniciativas vêm a reforçar as ações de divulgação e ampliação da visibilidade dos artigos publicados na AtoZ junto à comunidade Iberoamericana.

b) Lançamento do template AtoZLaTeX: Dando continuidade à adoção do LaTeX como o ambiente para a diagramação de artigos, a AtoZ disponibiliza, a partir deste número, um novo template para que os autores possam submeter seus artigos nesse formato. Esse template é composto por três arquivos: 1) o modelo/template propriamente dito no formato .tex, no qual são inseridos os dados básicos e o conteúdo do artigo; 2) o arquivo auxilar no formato .bib, no qual devem ser registradas as referências do artigo; e 3) um manual de uso do LaTeX, em ambiente Windows ou Linux. Esse material de apoio foi desenvolvido pelo bolsista de iniciação científica Marcelo Batista, o qual também auxiliou a equipe da Revista na implementação no ambiente LaTeX. A migração do formato de referências de ABNT para APA é um movimento adicional da AtoZ na agregação de material enviado por autores não brasileiros. Neste particular, alertamos os autores quanto a esta e outras mudanças no item Diretrizes para os Autores.

Nosso agradecimento aos colaboradores e leitores e um abraço da equipe editorial AtoZ! 